This item was submitted to Loughborough's Research Repository by the author.

Items in Figshare are protected by copyright, with all rights reserved, unless otherwise indicated.

\title{
Strain-gradient crystal-plasticity modelling of micro-cutting of b.c.c. single crystal
}

PLEASE CITE THE PUBLISHED VERSION

http://dx.doi.org/10.1007/s11012-015-0280-3

\section{PUBLISHER}

(C) Springer

\section{VERSION}

AM (Accepted Manuscript)

\section{PUBLISHER STATEMENT}

This work is made available according to the conditions of the Creative Commons Attribution-NonCommercialNoDerivatives 4.0 International (CC BY-NC-ND 4.0) licence. Full details of this licence are available at: https://creativecommons.org/licenses/by-nc-nd/4.0/

\section{LICENCE}

CC BY-NC-ND 4.0

\section{REPOSITORY RECORD}

Demiral, Murat, Anish Roy, and Vadim Silberschmidt. 2019. "Strain-gradient Crystal-plasticity Modelling of Micro-cutting of B.c.c. Single Crystal”. figshare. https://hdl.handle.net/2134/20560. 


\section{Meccanica \\ Strain-gradient crystal-plasticity modelling of micro-cutting of b.c.c. single crystal --Manuscript Draft--}

Manuscript Number:

Full Title:

Article Type:

Section/Category:

Keywords:

Corresponding Author:

Corresponding Author Secondary

Information:

Corresponding Author's Institution:

Corresponding Author's Secondary Institution:

First Author:

First Author Secondary Information:

Order of Authors:

Order of Authors Secondary Information:

Abstract:
Murat Demiral, Assistant Professor

Strain-gradient crystal-plasticity modelling of micro-cutting of b.c.c. single crystal

\section{S.I. : Computational Micromechanics of Materials}

Solids

Strain-gradient crystal-plasticity; orthogonal micro-cutting, brass single crystal; finiteelement analysis

Anish Roy

Loughborough University

Loughborough, UNITED KINGDOM

\section{Loughborough University}

Murat Demiral, Assistant Professor

Anish Roy

Vadim V. Silberschmidt, Professor

In recent years thanks to enhancements in design of advanced machines, laser metrology and computer control, ultra-precision machining has become increasingly important. In micromachining of metals the depth of cut is usually less than the average grain size of a polycrystalline aggregate; hence, a cutting process can occur entirely within a single crystal. The respective effect of crystallographic anisotropy requires development of machining models that incorporate crystal plasticity for an accurate prediction of micro-scale material removal under such conditions. To achieve this, a 3D finite-element model of orthogonal micro-cutting of a single crystal of b.c.c. brass was implemented in a commercial software ABAQUS/Explicit using a user-defined subroutine VUMAT. Strain-gradient crystal-plasticity theories were used to demonstrate the influence of evolved strain gradients on the cutting process for different cutting directions. 


\title{
Strain-gradient crystal-plasticity modelling of micro-cutting of
} b.c.c. single crystal

\author{
Murat Demiral $^{1}$, Anish Roy*2 ${ }^{2}$, Vadim V. Silberschmidt ${ }^{2}$ \\ ${ }^{1}$ Department of Mechanical Engineering, University of Turkish Aeronautical Association, 06790 Ankara, \\ Turkey \\ ${ }^{2}$ Wolfson School of Mechanical and Manufacturing Engineering, Loughborough University, LE11 3TU UK \\ *Corresponding author. Tel.: +44 1509227 566; E-mail: A.Roy3@lboro.ac.uk
}

\begin{abstract}
In recent years thanks to enhancements in design of advanced machines, laser metrology and computer control, ultra-precision machining has become increasingly important. In
\end{abstract} micromachining of metals the depth of cut is usually less than the average grain size of a polycrystalline aggregate; hence, a cutting process can occur entirely within a single crystal. The respective effect of crystallographic anisotropy requires development of machining models that incorporate crystal plasticity for an accurate prediction of micro-scale material removal under such conditions. To achieve this, a 3D finiteelement model of orthogonal micro-cutting of a single crystal of b.c.c. brass was implemented in a commercial software ABAQUS/Explicit using a user-defined subroutine VUMAT. Strain-gradient crystal-plasticity theories were used to demonstrate the influence of evolved strain gradients on the cutting process for different cutting directions.

Keywords: Strain-gradient crystal-plasticity; orthogonal micro-cutting, brass single crystal; finite-element analysis

\section{Introduction and motivation}

With continuous miniaturization of industrial products, understanding of micro-scale deformation of materials increases in its significance. In micromachining of metals, the depth of cut is usually less than the average grain size of a polycrystalline aggregate. As a result, the cutting action may occur entirely within a single crystal. In the experimental micromachining studies, such parameters as the cutting force, shear angle, dynamic shear stress and chip thickness were observed to depend on the orientation of the cutting direction and the cutting-plane normal with respect to the crystal axis. This is naturally 
explained by the fact that single crystals are highly 1 anisotropic in their physical properties [1]. To

elucidate the underlying physics for the micromachining process, different analytical and numerical models were proposed.

Sato [2] tried to use the continuum yield theory to analyse changes in the shear stress and shear angle with material anisotropy, but the attempt was unsuccessful as the value of the shear angle was in the reverse phase to shear stress. Later, Sato et al. [3] calculated the shear angle from the vector sum of slip directions on active slip systems based on the assumption that the amount of shearing on the slips system is proportional to its Schmid factor. Shirakashi et al. [4] used the Hill's orthogonal plastic anisotropy theory to predict shear angles in cutting f.c.c. single crystals. This approach, however, was found to be not suitable for predicting machining forces. Lee and Zhou [5] and Lee et al. [6] used an effective Taylor factor to predict a shear angle in single-crystal cutting. For each crystallographic orientation, this factor was calculated for all possible shear angles. However, it was observed (based on the minimum energy criterion) that a range of shear angles might exist for a given type of material's anisotropy. The authors proposed that the most likely shear angle was the one corresponding to the most negative texture-softening factor among the ones with the same minimum shear strength. This work was then extended using the Merchant's model to predict the change in cutting forces with crystallographic orientation. Recently,
Kota and Ozdoganlar [7] developed a plasticitybased model of a machining force combining the Bishop and Hill's crystal plasticity models with the Merchant's orthogonal cutting model; the experimental validation of the model was carried out. All these analytical models were developed based on assumption of plain-strain orthogonal cutting.

Continuum numerical models of micro-scale material removal processes compared to analytical ones are very limited. Liang et al. [8] attempted to predict the effects of crystal orientation and grain boundaries on cutting forces using 2D finiteelement (FE) analysis. However, in that study deformation was confined only to the elastic region. Liu and Melkote [9] developed a 3D FE model of micro-cutting including strain-gradient effects. In their study the crystallographic anisotropy was not accounted for in the constitutive equations. Recently, Zahedi et al. [10] and Demiral et al. [11] investigated the effect of crystallographic anisotropy on a response of copper single crystal using a 3D smoothed particle hydrodynamics/FE crystal plasticity model and a strain-gradient crystal-plasticity FE model, respectively.

At the same time, recent experiments demonstrated that metallic materials displayed a strong size effect at the micron and sub-micron scales $[12,13]$. This phenomenon was attributed to the presence of geometrically necessary dislocations (GNDs) associated with nonuniform 
plastic deformation. In this regard, it becomes

1 essential to account for strain gradients, arising in 2 cutting processes, for accurate prediction of micro-scale material removal in machining models. Since conventional crystal-plasticity theories possess no intrinsic material lengths, they cannot explain the size-dependent material's behaviour at small scales. In this study, an enhanced modelling scheme of a strain-gradient crystal-plasticity (EMSGCP) theory proposed by Demiral [14] is used. This work aims to demonstrate the influence of strain gradients on the deformation response of b.c.c. single-crystal brass in the machining process.

This paper is organized as follows: the details of the developed finite-element model of microcutting are introduced in Section 2. Section 3 presents its validation against experimental data and demonstrates its predictive capabilities for different cutting directions. Finally, concluding remarks are given in Section 4. The theory for a strain-gradient crystal-plasticity model with governing equations is presented in Appendix.

\section{Finite-element}

\section{implementation}

A FE model of the orthogonal micro-machining experiment on a workpiece with dimensions 20 $\mu \mathrm{m} \times 20 \mu \mathrm{m} \times 0.48 \mu \mathrm{m}$ (Fig. 1) was developed [11]. Considering a compromise between the accuracy and time of computations, 29600 eightnode linear brick elements (C3D8) were used to discretise the sample, with a minimum element size of $60 \mathrm{~nm}$ in the process zone. The cutting tool, modelled as a rigid body with rake and clearance angles of $0^{\circ}$, was displaced in the cutting direction ([abc] in Fig. 1) with a velocity of $-1300 \mathrm{~mm} / \mathrm{s}$. A depth of cut $\left(a_{p}\right)$ was fixed at $2 \mu \mathrm{m}$ and the maximum cutting length of $1.2 \mu \mathrm{m}$ was considered in the simulations. Friction was neglected throughout the simulation. Chip separation from the workpiece material was achieved with the use of an element-deletion module available in ABAQUS/Explicit [15]; the Taylor cumulative shear strain on all slip systems $(\tilde{\gamma})$ was employed as the failure criteria. Physical shear failure occurred when this parameter reached a critical value of 3 .

\section{Fig. 1}

Here, machining in a single crystal of $\beta$-brass with a b.c.c. crystalline structure is studied. It was known that the active slip system of this structure is $\{110\}<111>$ [16]; therefore, only this set - from three potential system in b.c.c. materials - was enabled in the simulations. Three material parameters, $C_{11}=131.0 \mathrm{GPa}, C_{12}=115.0 \mathrm{GPa}$, $C_{44}=92.0 \mathrm{GPa}$, were used to define the elasticity tensor for the $\beta$-brass crystal [17], the respective plasticity parameters used in the simulations are listed in Table 1. The simulations were performed using the EMSGCP and enhanced modelling scheme of crystal-plasticity (EMCP) theories implemented in the finite-element code 
ABAQUS/Explicit [15] using the user-defined

1 material subroutine (VUMAT). Their comparison 2 3 elucidates the amount of evolving strain gradients during the deformation process. The summary of the theories is given in Appendix.

\section{Table 1}

\section{Results and discussion}

different rotation angles of the (llll $\left.\begin{array}{lll}1 & 0 & 1\end{array}\right)$-brass. Apparently, $\phi$ varies remarkably with $\theta$, resulting in the corresponding values of $42^{\circ}, 62^{\circ}, 57^{\circ}$ and $39^{\circ}$ for $\theta=0^{\circ},-35^{\circ},-45^{\circ}$ and $-90^{\circ}$, respectively (Fig. 3). In ultra-precision machining, a large shear angle is associated with continuous chip formation and good surface finish [22]. Therefore, among the cutting directions investigated here, $\theta=$ $-35^{\circ}$ and $-45^{\circ}$ are preferable for micro-cutting of brass single crystals for a better surface finish. To check the accuracy of the model, the obtained results were compared with the experiments presented in [16]. Our FE results demonstrated that the shear angles were predicted accurately for $\theta$ equals to $-35^{\circ}$ and $-45^{\circ}$, while some deviations were observed for $\theta=0^{\circ}$ and $-90^{\circ}$. However, the general trends of the curves describing a variation of $\phi$ for different $\theta$ values, obtained numerically and experimentally, were in good agreement. Fig. 3 presents also the analytical results based on the analysis of the Schmid factor reported in [16]. Although the shear angles were captured successfully for $\theta=0^{\circ}$ and $-90^{\circ}$ with this approach, a significant deviation was observed for $\theta=-35^{\circ}$, $-45^{\circ}$. These results suggest that our numerical predictions are more in accord with the experiments when compared to the analytical ones. It should be emphasized that the frictional, thermal and viscous effects were not accounted in the present model; this might be one of the reasons for overestimation of $\phi$ values at $\theta=0^{\circ}$ and $-90^{\circ}$ using $\mathrm{FE}$ analysis.
Fig. 2

Fig. 3

Evolution of the calculated cutting forces with an increasing cutting length for different $\theta$ values of the $\left(\begin{array}{lll}1 & 0 & 1\end{array}\right) \beta$-brass is shown in Fig. 4. The cutting force was found to vary with different cutting directions. For instance, the measured value of the cutting force at the [- $\left.\begin{array}{lll}-1 & 2.015 & 1\end{array}\right]$ and [ $\left[\begin{array}{lll}1 & 1.414 & -1\end{array}\right]$ directions corresponding to $\theta=-35^{\circ}$ and $-45^{\circ}$, 
respectively, are larger compared to that in the [0 -

$\left.\begin{array}{lll}1 & 1 & 0\end{array}\right]$ and $\left[\begin{array}{lll}-1 & 0 & 1\end{array}\right]$ directions $\left(\theta=0^{\circ}\right.$ and $90^{\circ}$, 3 respectively). It should be emphasized that the 4 fluctuations observed in the cutting force occur 6 due to variation in the shear angle during the cutting process [23].

\section{Fig. 4}

FE simulations were also performed using the EMCP theory. The results obtained with this approach demonstrate that while the EMSGCP theory predicted a cutting force that increased with an increase in the cutting length, the EMCP theory predicted the force value, stabilised at larger cutting-length magnitudes (Fig. 4). These observations are valid for all the studied cutting directions. The difference in the predicted cutting forces for the two theories was due to the fact that the EMSGCP theory characterises the contribution of strain gradients and its evolution during the inhomogeneous cutting process, and, hence, the strain-hardening rate was higher. The averages of force magnitudes for the cutting lengths of $0.6 \mu \mathrm{m}$ and $1.2 \mu \mathrm{m}$ were calculated; they are listed in Table $3\left(F_{E M C P}\right.$ and $F_{E M S G C P}$ are the cutting force obtained with the EMCP and EMSGCP theories, respectively). As expected, the values predicted with the EMSGCP theory were noticeably larger (8-9\%) when compared to those based on the EMCP theory. It was noted that the extent of respective difference was not significantly sensitive to the cutting direction.

\section{Table 3}

Apparently, the observed differences in realisation of micro-cutting in different directions should be underpinned by some processes at micro scale. Fig. 5 presents the distributions of the sum of magnitudes of effective GND density in all the slip systems $\left(\sum\left|n_{G}^{(\alpha)}\right|\right)$ for different cutting directions. This indicates that GNDs are significant on the chip surface in contact with the tool for $\theta=0^{\circ}$, whereas for other directions, the density of GNDs are larger both on that surface and in the primary deformation zone. To get an insight into the distribution of GNDs, the total accumulative shear strain on all slip systems $\tilde{\gamma}$ was checked since their density is directly proportional to the gradients of effective plastic strain. For $\theta=0^{\circ}$, most of the shear activity and also its variation was observed on the chip surface; hence, the evolving GNDs are observed there. For $\theta=-35^{\circ},-45^{\circ}$, shearing occurred on the chip surface and in the primary deformation zone, but with to a higher extent in the former. However, the variation in $\tilde{\gamma}$ were observed in both regions; hence, an increase in the GNDs was found there. For $\theta=90^{\circ}, \tilde{\gamma}$ was more evenly distributed in both regions, but its variation was more pronounced in the primary deformation zone; as a result, more GNDs were observed to occur in this region.

Fig. 5 


\section{Concluding remarks}

1

2

${ }_{4}^{3}$ In this paper, a numerical implementation of an

enhanced model of strain-gradient crystal plasticity was used to demonstrate predictive capabilities of the theory in assessment of the effect of evolved strain gradients on the cutting process for different cutting directions of b.c.c. single crystals of $\beta$-brass. The shear angles predicted for different $\theta$ values using our $\mathrm{FE}$ model are in better agreement with the experimental data than those obtained analytically. It was noted that the amount of evolved GNDs was not significantly sensitive to the cutting direction, but their spatial positions varied considerably: for one orientation they were mostly localised on the chip surface while in other cases they also evolved in the primary shear zone. In this study, only mechanical processes - most prominent in micro-cutting - were considered. The next natural step would be to further develop the suggested approach incorporating also frictional, thermal and viscous effects into the constitutive equations. is indicated by $\nabla$, incremental changes in variables due to temporal evolution are indicated by a $\Delta$ symbol. A subscript $G$ indicates GNDs and $S$ implies statistically stored dislocations (SSDs).

In the EMSGCP theory, the initial strength of the slip systems $\left(\left.g_{T}^{\alpha}\right|_{t=0}\right)$, i.e. the critical resolved shear stress (CRSS), is governed by pre-existing GNDs in the workpiece together with SSDs, i.e. $\left.g_{T}^{\alpha}\right|_{t=0}=\sqrt{\left(\left.g_{S}^{\alpha}\right|_{t=0}\right)^{2}+\left(\left.g_{G}^{\alpha}\right|_{t=0}\right)^{2}}$. In this theory, $\left.g_{\mathrm{S}}^{\alpha}\right|_{t=0}$ and $\left.g_{\mathrm{G}}^{\alpha}\right|_{t=0}$ were linked with initial SSD $\left(\left.\rho_{\mathrm{S}}\right|_{t=0}\right)$ and GND $\left(\left.\rho_{\mathrm{G}}\right|_{t=0}\right)$ densities as $\left.g_{S}^{\alpha}\right|_{t=0}=K \sqrt{\left.\rho_{S}\right|_{t=0}},\left.g_{G}^{\alpha}\right|_{t=0}=K \sqrt{\left.\rho\right|_{t=0}(\overline{S / V})^{2}}$ via the constant, $K$, similar to the Taylor relation. The GND density term was expressed as a function of the normalized surface-to-volume $(\overline{S / V})$ ratio (hence, dimensionless) for the component under study. In this study the surfaceto-volume ratio of the workpiece materials was normalized with an idealised workpiece geometry corresponding to $S / V=1 \mu \mathrm{m}^{-1}$.

The evolution of slip resistance during loading is the result of hardening due to the SSDs $\left(\Delta g_{S}^{\alpha}\right)$ and GNDs $\left(\Delta g_{G}^{\alpha}\right)$ on the slip system, which follows:

$$
\begin{gathered}
\mathrm{g}_{T}^{\alpha}=\left.\mathrm{g}_{T}^{\alpha}\right|_{\mathrm{t}=0}+\sqrt{\left(\Delta \mathrm{g}_{S}^{\alpha}\right)^{2}+\left(\Delta \mathrm{g}_{G}^{\alpha}\right)^{2}}, \\
\Delta \mathrm{g}_{S}^{\alpha}=\sum_{\beta=1}^{\mathrm{N}} \mathrm{h}_{\alpha \beta} \Delta \gamma^{\beta}, \Delta \mathrm{g}_{G}^{\alpha}=\alpha_{T} \mu \sqrt{\mathrm{bn}_{G}^{\alpha}},
\end{gathered}
$$


here, $h_{\alpha \beta}, \alpha_{\mathrm{T}}, \mu, b$ and $n_{G}^{\alpha}$ corresponds to the sliphardening modulus, the Taylor coefficient, the 4 shear modulus, the Burgers vector and the effective density of geometrically necessary dislocations, respectively.

$$
\dot{\gamma}^{\alpha}=\dot{\gamma}_{0}^{\alpha} \operatorname{sgn}\left(\tau^{\alpha}\right)\left|\frac{\tau^{\alpha}}{g_{T}^{\alpha}}\right|^{n}
$$

where $\dot{\gamma}_{0}^{\alpha}$ is the reference strain rate, $n$ is the macroscopic rate-sensitivity parameter, $\tau^{\alpha}$ is the resolved shear stress, $g_{T}^{\alpha}$ is the strength of the slip system $\alpha$ at the current time, and $\operatorname{sgn}(*)$ is the signum function of $*$.

To demonstrate the relative contribution of the evolution of GNDs to local hardening of the material in EMSGCP, an enhanced model of crystal-plasticity (EMCP) was introduced, where the incipient density of GNDs in the experimental samples was accounted for, but not GNDs evolving in the course of deformation. This model can be derived from the proposed EMSGCP theory by setting $\Delta g_{G}^{\alpha}=0[11]$.

\section{Acknowledgement}

MD was supported with a fellowship from The Scientific and Technological Research Council of Turkey (TÜBITAK 2232, project no: 114C199).

\section{References}

[1] Lawson BL, Kota N, Ozdoganlar OB (2008)

Effects of crystallographic anistropy on orthogonal micromachining of single-crystal aluminum. J Manuf Sci Eng 130(3):031116. 
[2] Sato M, Kato K, Tuchiya K (1978) Effect of 1 material and anisotropy upon the cutting 2 3 4 5 6 7

mechanism. Trans JIM 9: 530-536.

[3] Sato M, Kato Y, Aoki S, Ikoma, A (1983)

Effects of Crystal Orientation on the Cutting Mechanism of the Aluminum Single Crystal: 2nd Report: On the (111) plane and the (112) end Cutting. Bulletin of JSME 26(215):890-896.

[4] Shirakashi T, Yoshino M, Kurashima H (1991) Study on cutting mechanism of single crystal based on simple shear plane model. Int J Japan Soc Precis Eng 25(2):96-97.

[5] Lee WB, Zhou M (1993) A theoretical analysis of the effect of crystallographic orientation on chip formation in micromachining. Int J Mach Tools Manuf 33:439-447.

[6] Lee WB, Cheung CF, To S (2002) A microplasticity analysis of micro-cutting force variation in ultra-precision diamond turning. $\mathbf{J}$ Manuf Sci Eng 124(2):170-177.

[7] Kota N, Ozdoganlar, OB (2010) A modelbased analysis of orthogonal cutting for singlecrystal fcc metals including crystallographic anisotropy. Mach Sci Tech 14(1):102-127.

[8] Liang Y, Moronuki N, Furukawa, Y (1994) Calculations of the effect of material anisotropy on microcutting processes. Precis Eng 16(2):132138.

[9] Liu K, Melkote SN (2007) Finite element analysis of the influence of tool edge radius on size effect in orthogonal micro-cutting process. Int J Mech Sci 49:650-660.

[10] Zahedi SA, Demiral M, Roy A, Silberschmidt VV (2013) FE/SPH modelling of orthogonal micro-machining of f.c.c. single crystal. Comp Mater Sci 78:104-109.

[11] Demiral M, Roy A, El Sayed T, Silberschmidt VV (2014) Numerical modelling of micro-machining of fcc single crystal: Influence of strain gradients. Comp Mater Sci 94: 273-278.

[12] Huang Y, Qu S, Hwang KC, Li M, Gao H (2004) A conventional theory of mechanismbased strain gradient plasticity. Int J Plast 20(4):753-782.

[13] Ertürk I, Van Dommelen JAW, Geers MGD (2014) Gradient crystal plasticity modelling of anelastic effects in particle strengthened metallic thin films. Meccanica 49:2657-2685.

[14] Demiral M (2012) Enhanced gradient crystalplasticity study of size effects in b.c.c. metal. Dissertation, Loughborough University, UK.

[15] Dassault Systemes (2013) Abaqus 6. 13 Analysis User Manual.

[16] Ueda K, Iwata K, Nakayama K (1980) Chip formation mechanism in single crystal cutting of $\beta$-brass. CIRP Annals-Manuf Tech 29(1):41-46.

[17] Jona F, Marcus PM (2001) Structural and elastic properties of $\beta$-brass. Journal of Physics: Condensed Matter 13(23):5507.

[18] Jia N, Roters F, Eisenlohr P, Kords C, Raabe D (2012) Non-crystallographic shear banding in crystal plasticity FEM simulations: Example of texture evolution in $\alpha$-brass. Acta Mater 60(3):1099-1115.

[19] Beyerlein IJ, Mara NA, Bhattacharyya D, Alexander DJ, Necker CT (2011) Texture evolution via combined slip and deformation 
twinning in rolled silver-copper cast eutectic

1 nanocomposite. Int J Plast 27(1):121-146.

[20] Peirce D, Asaro R, Needleman A (1982) An 4 analysis of nonuniform and localized deformation 6 in ductile single crystals. Acta Metallur 30:10871119.

[21] Schulze D, Paufler P (1979) Physikalische Grundlagenmechanischer Festkörpereigenschaften, Akademie-Verlag, Berlin.

[22] Lee WB (1990) Prediction of microcutting force variation in ultra-precision machining. Precis Eng 12(1):25-28.

[23] Tajalli SA, Movahhedy MR, Akbari J (2014) Simulation of orthogonal micro-cutting of FCC materials based on rate-dependent crystal plasticity finite element model. Comp Mater Sci $86: 79-87$.

[24] Demiral M, Roy A, Silberschmidt VV (2013) Indentation studies in bcc crystals with enhanced model of strain-gradient crystal plasticity. Comp Mater Sci 79:896-902.

\section{Figure captions}

Fig. 1: Dimensions and coordinate system for orthogonal cutting of single-crystal workpiece material

Fig. 2: Numerically obtained chip morphologies for different rotation angles of ( $\left.\begin{array}{lll}1 & 0 & 1\end{array}\right) \beta$-brass

Fig. 3: Variation of shear angle with rotation angle obtained in experiments [16], simulations (via the EMSGCP theory) and analytical solutions [16] for (1 010 ) $\beta$-brass
Fig. 4: Evolution of cutting forces obtained using EMSGCP and EMCP theories for different cutting directions

Fig. 5: Distribution of effective density of GNDs in all slip systems $\sum\left|n_{G}^{(\alpha)}\right|$ (top) and total accumulative shear strain on all slip systems $(\tilde{\gamma})$ (bottom) at cutting length of $2.2 \mu \mathrm{m}$ obtained with FE simulations using EMSGCP theory for $\left(\begin{array}{lll}1 & 0 & 1\end{array}\right)$ single-crystal $\beta$-brass for various $\theta$

\section{Table captions}

Table 1: Plastic parameters used in FE simulations [11,18-21]

Table 2: Different cutting directions ([abc]) and cutting-plane normals ([def]) for different $\theta$ values of [ $\left[\begin{array}{lll}1 & 0 & 1\end{array}\right]$ axis parallel to the observation direction (see Fig. 1)

Table 3: Average cutting forces obtained with EMSGCP and EMCP theories and their relative differences for different $\theta$ values. 


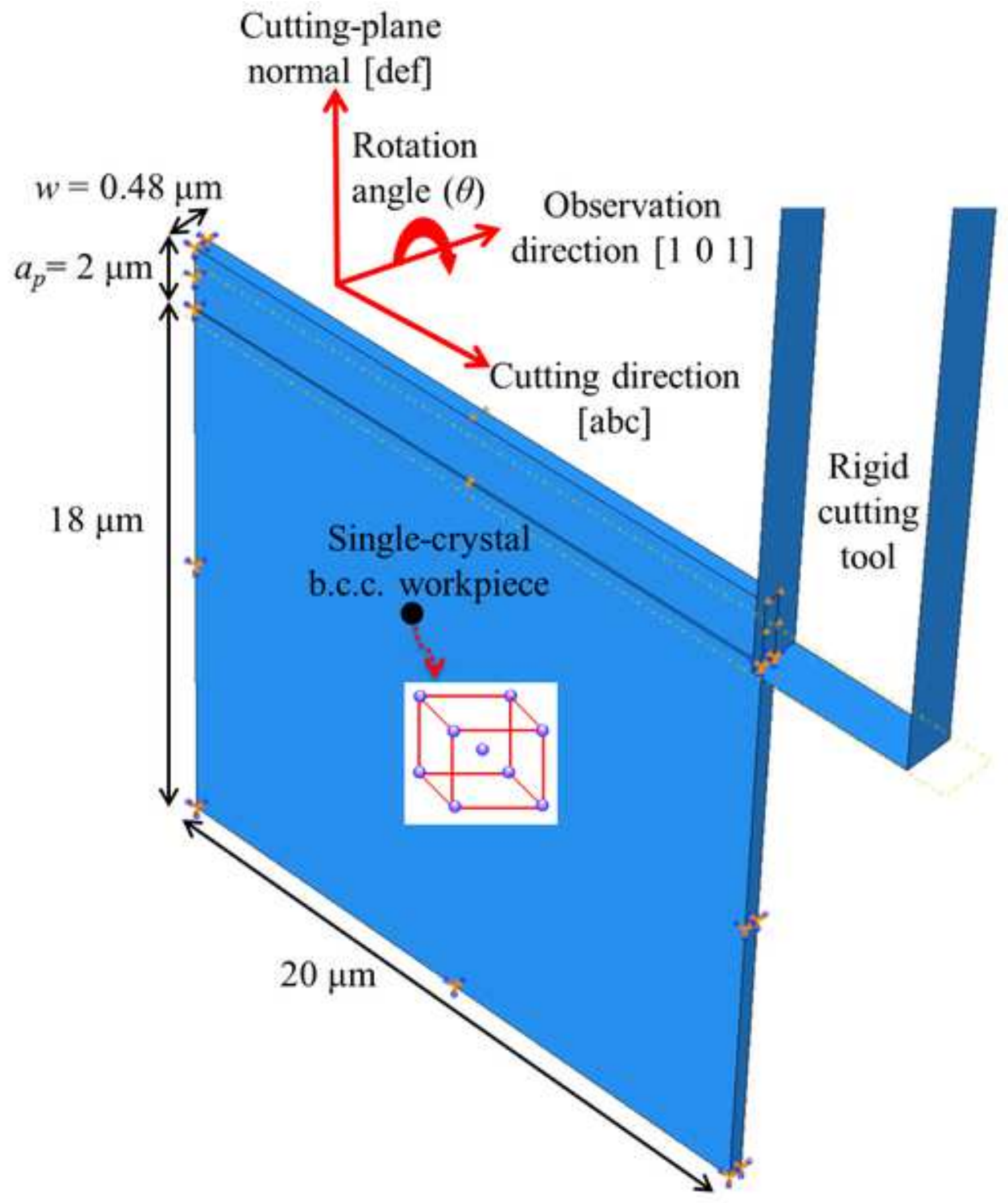




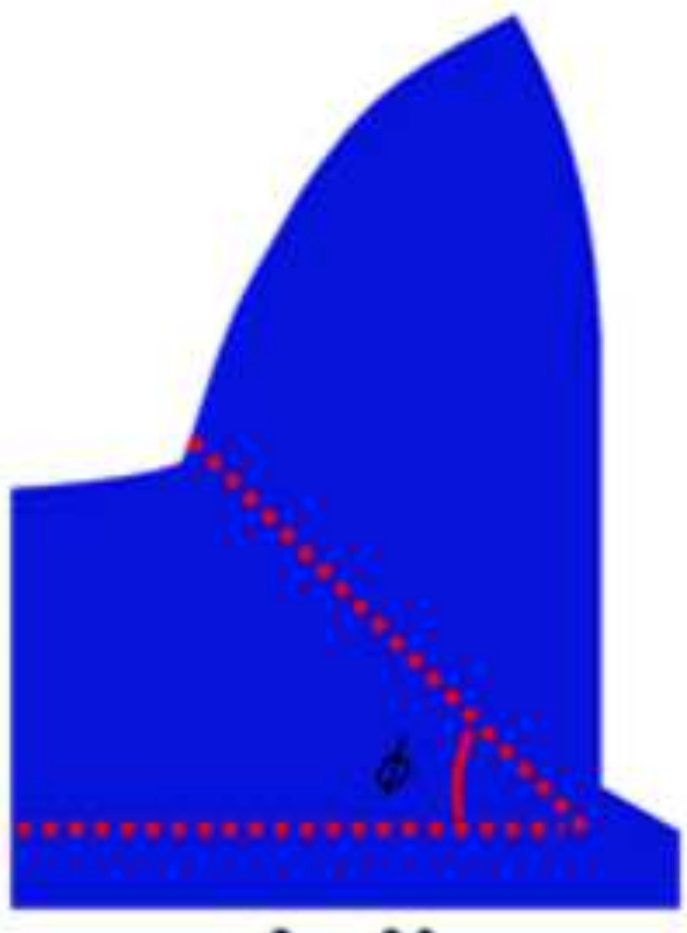

$\theta=0^{\circ}$

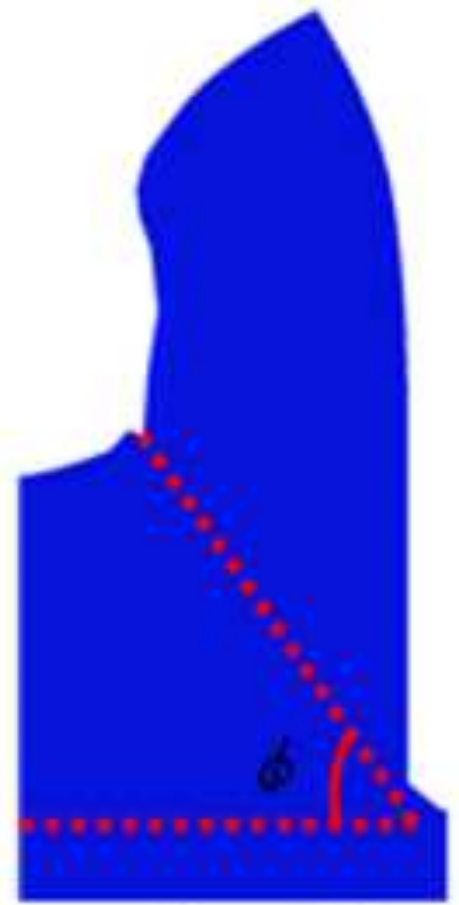

$\theta=-35^{\circ}$
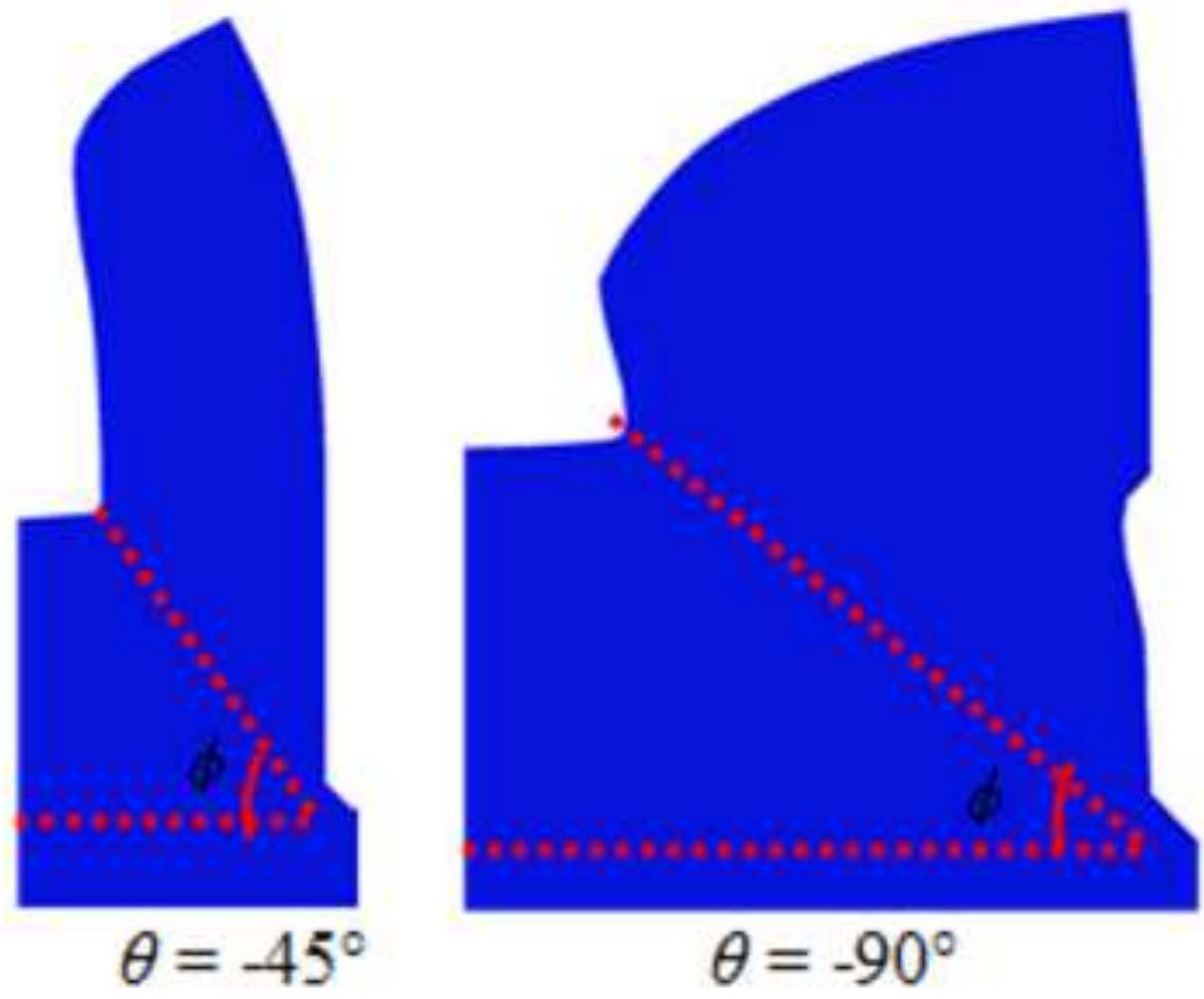


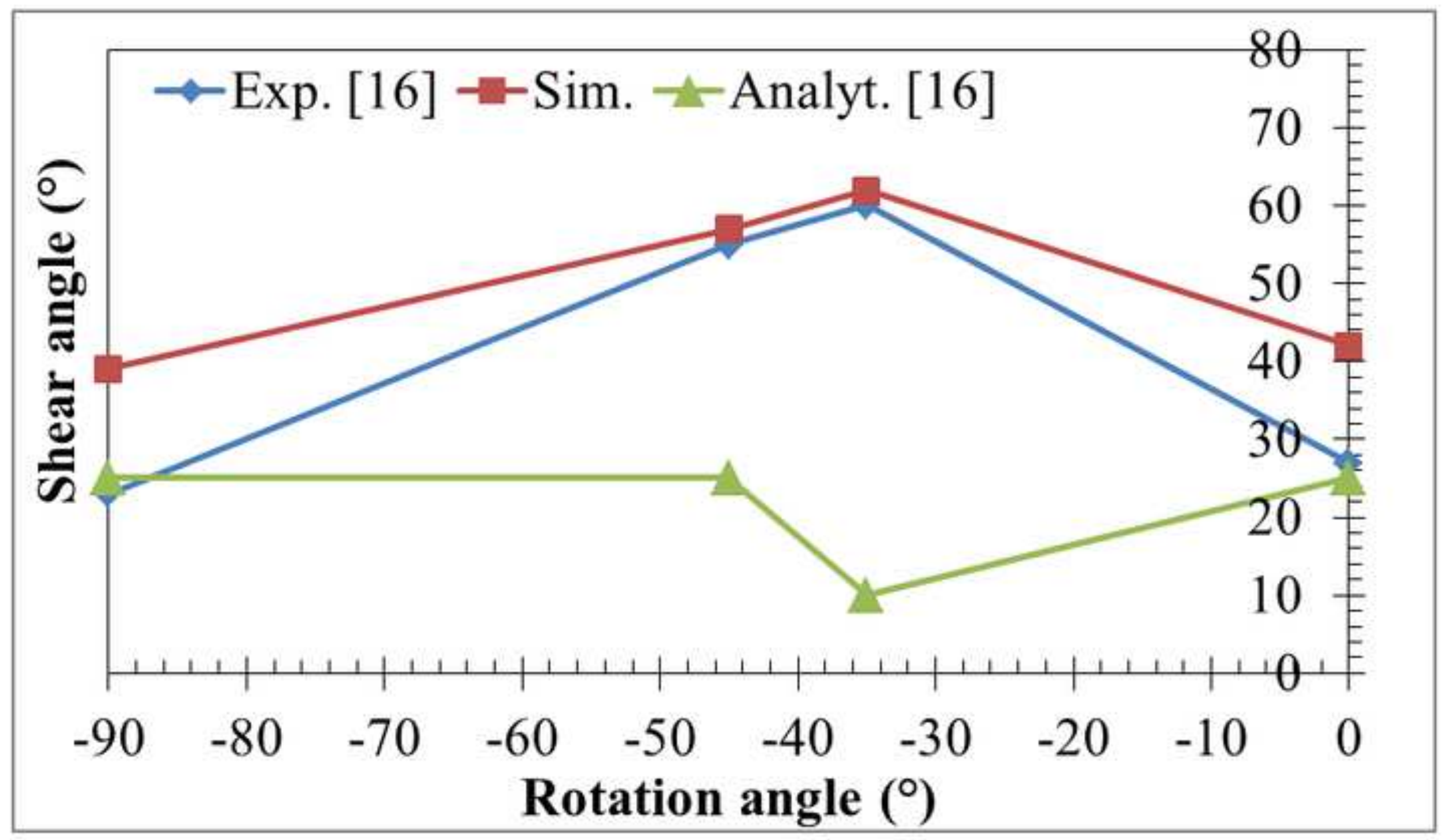



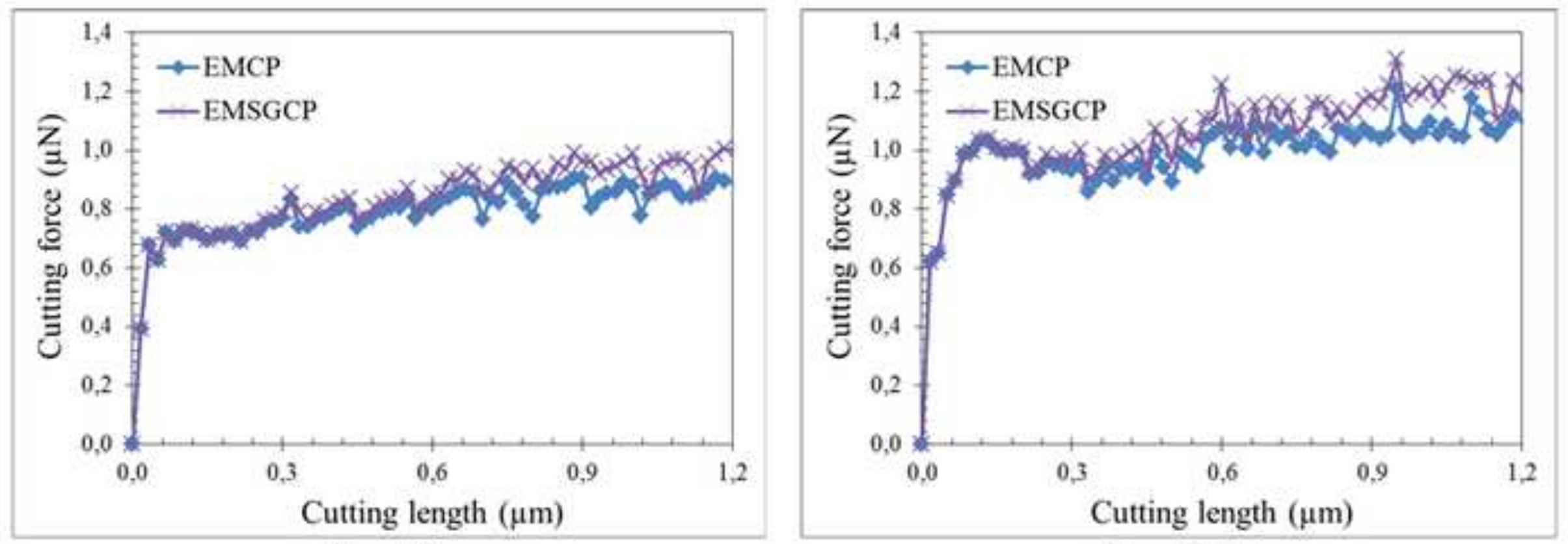

$$
\theta=0^{\circ}
$$

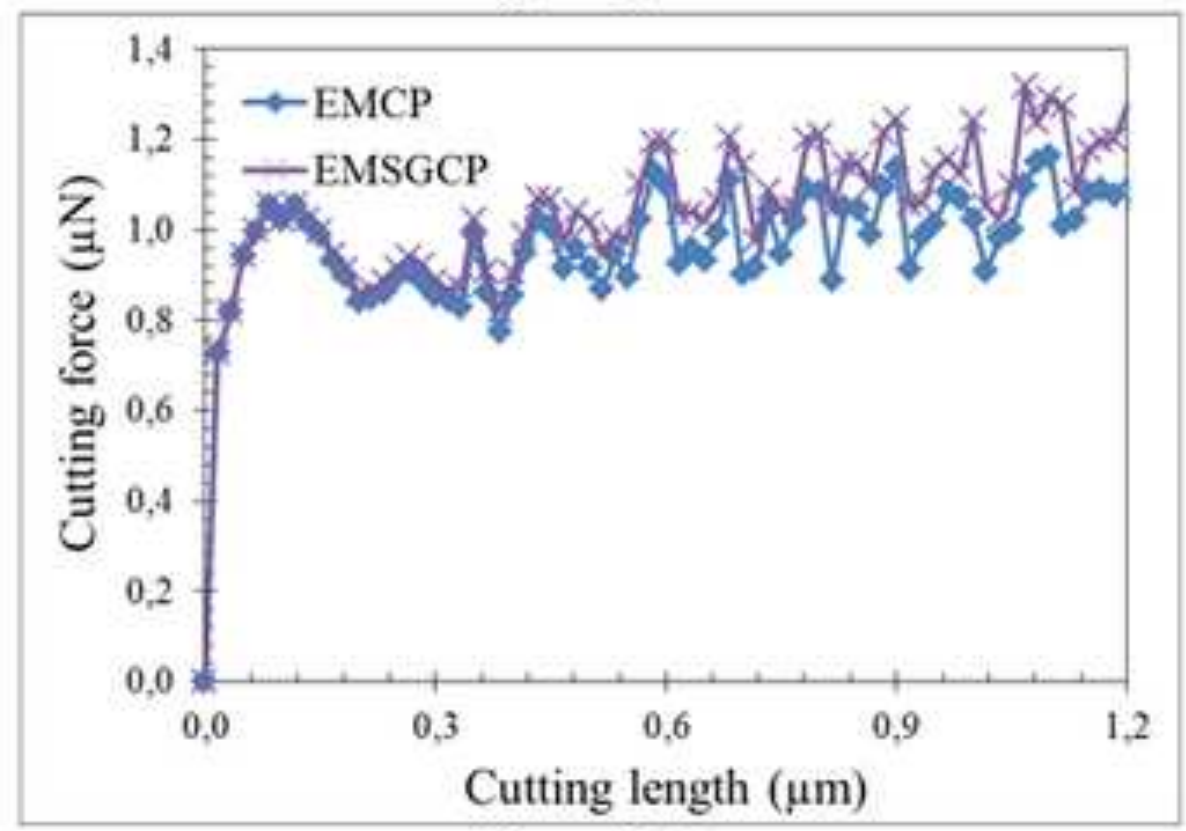

$$
\theta=-45^{\circ}
$$

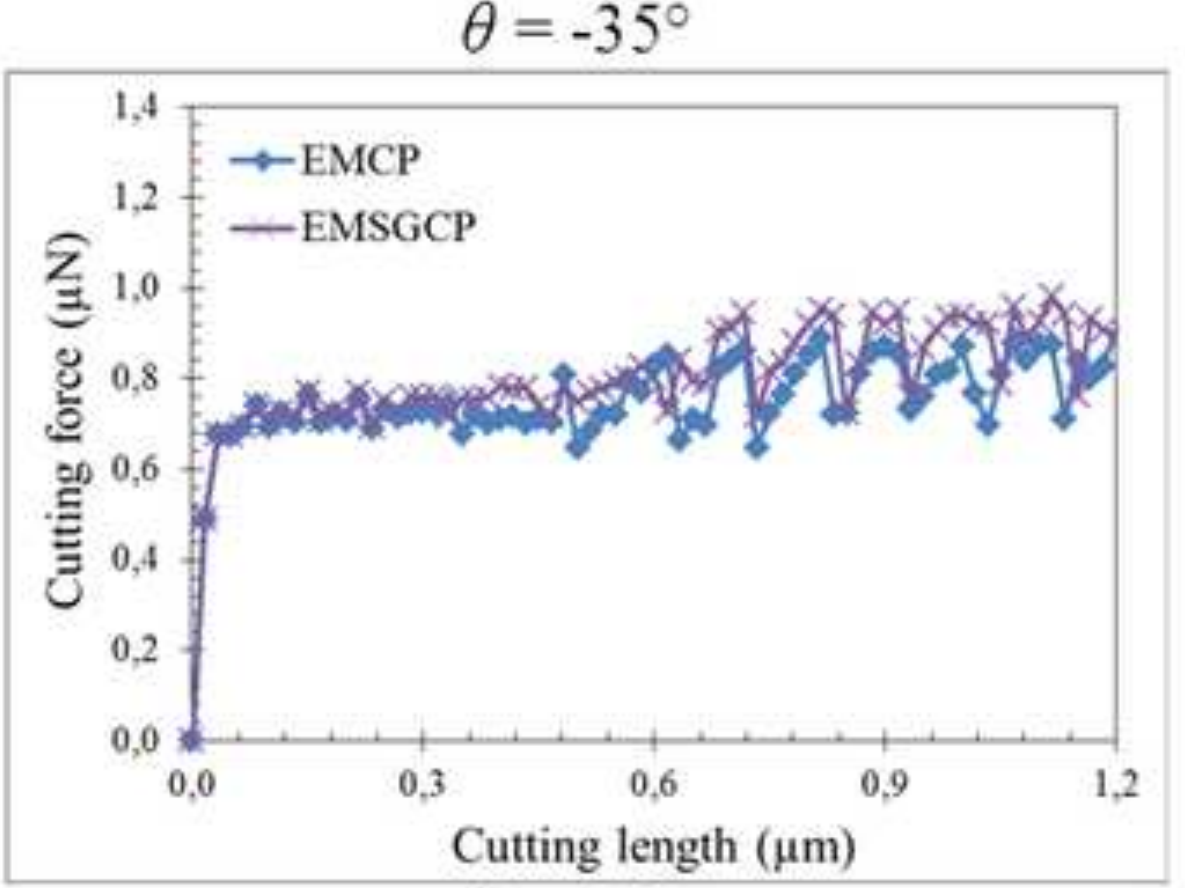

$$
\theta=-90^{\circ}
$$


$\sum\left|n_{c}^{(a)}\right|\left(m m m^{-1}\right)$

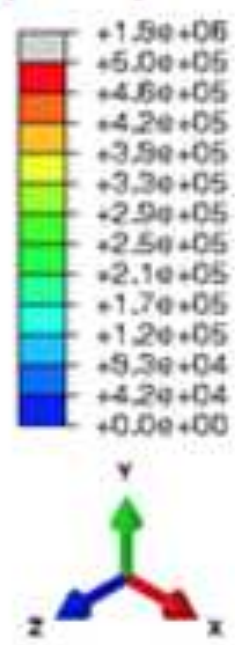

$\tilde{\gamma}$

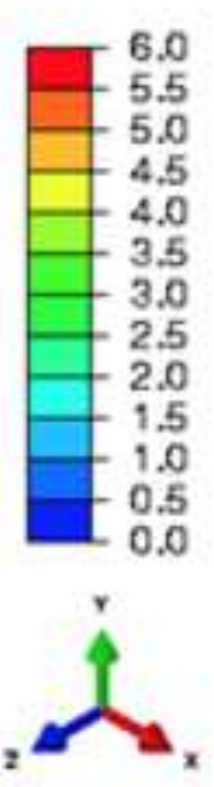

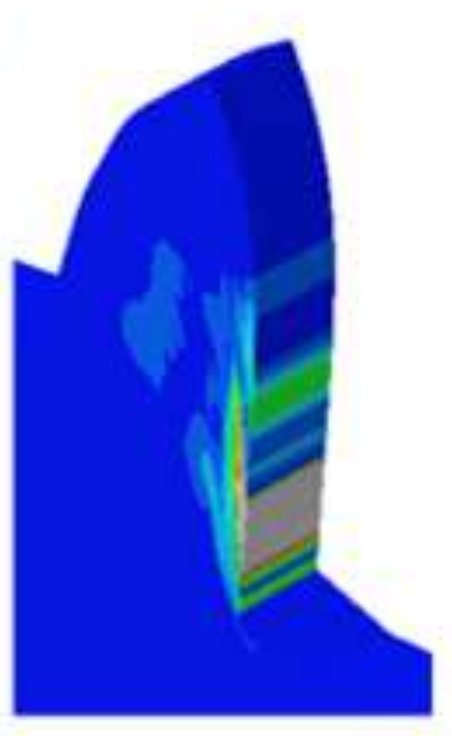
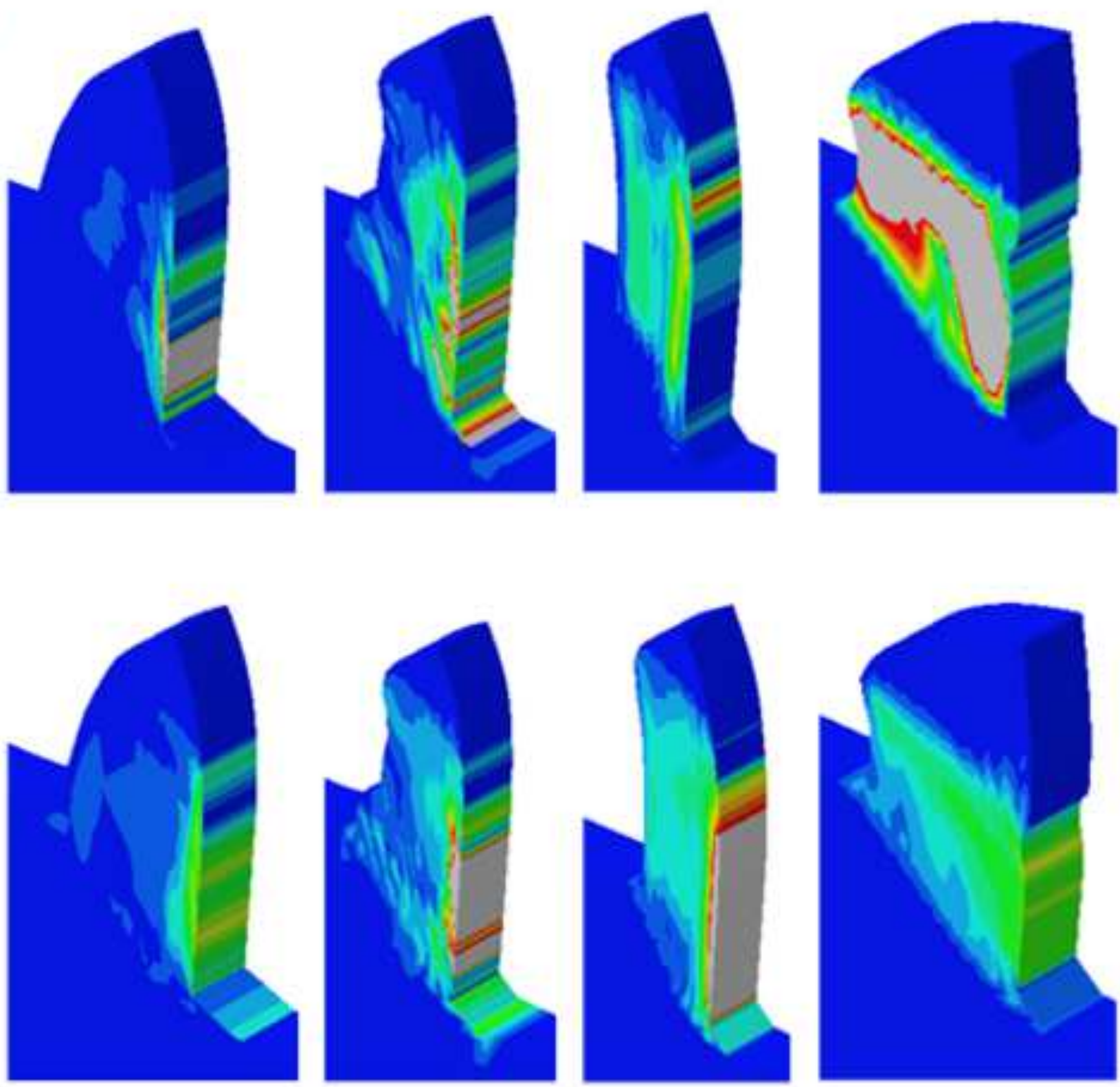

$\theta=0^{\circ}$

$\theta=-35^{\circ}$

$\theta=-45^{\circ}$

$\theta=90^{\circ}$ 


\begin{tabular}{cccc}
\hline$\dot{\gamma}_{0}^{\alpha}\left(\mathrm{s}^{-1}\right)$ & $10^{-3}$ & $K(\mathrm{MPa} \mathrm{mm})$ & 0.04 \\
\hline$n$ & 20 & $\mu_{\mathrm{s}}(\mathrm{GPa})$ & 27.12 \\
\hline$q$ & 1 & $b(\mathrm{~mm})$ & $2.56 \times 10^{-7}$ \\
\hline$h_{0}(\mathrm{MPa})$ & 294 & $\left.\rho_{s}\right|_{t=0}\left(\mathrm{~mm}^{-2}\right)$ & $6.810^{5}$ \\
\hline$\left.g_{T}^{\alpha}\right|_{\mathrm{sat}}(\mathrm{MPa})$ & 60 & $\left.\rho\right|_{t=0}\left(\mathrm{~mm}^{-2}\right)$ & $5.010^{4}$ \\
\hline$\alpha_{\mathrm{T}}$ & 0.7 & $\overline{S / V}$ & 4.36 \\
\hline
\end{tabular}




\begin{tabular}{|c|c|c|c|c|}
\hline$\theta$ & $0^{\circ}$ & $-35^{\circ}$ & $-45^{\circ}$ & $-90^{\circ}$ \\
\hline$[a b c]$ & {$\left[\begin{array}{lll}0 & -1 & 0\end{array}\right]$} & {$\left[\begin{array}{llll}-1 & 2.015 & 1\end{array}\right]$} & {$\left[\begin{array}{llll}1 & 1.414 & -1\end{array}\right]$} & {$\left[\begin{array}{lll}-1 & 0 & 1\end{array}\right]$} \\
\hline [def] & {$\left[\begin{array}{lll}-1 & 0 & 1\end{array}\right]$} & {$[2.0152-2.015]$} & {$[1-1.414-1]$} & {$\left[\begin{array}{lll}0 & 1 & 0\end{array}\right]$} \\
\hline
\end{tabular}




\begin{tabular}{cccc}
\hline$\theta$ & $F_{\mathrm{EMCP}}(\mu \mathrm{N})$ & $F_{\mathrm{EMSGCP}}(\mu \mathrm{N})$ & $\begin{array}{c}\left(F_{\mathrm{EMSGCP}}-F_{\mathrm{EMCP}}\right) / \\
F_{\mathrm{EMSGCP}}(\%)\end{array}$ \\
\hline $0^{\circ}$ & 0.853 & 0.929 & 8.18 \\
\hline$-35^{\circ}$ & 1.063 & 1.165 & 8.81 \\
\hline$-45^{\circ}$ & 1.027 & 1.139 & 9.86 \\
\hline$-90^{\circ}$ & 0.801 & 0.875 & 8.48 \\
\hline
\end{tabular}

